\title{
Sulphonate utilization by enteric bacteria
}

\author{
Maria R. URia-Nickelsen, EdWARD R. LeadbeTter* and Walter GodchauX III \\ Department of Molecular and Cell Biology, The University of Connecticut, Storrs, CT 06269-2131, USA
}

(Received 6 July 1992; revised 18 September 1992; accepted 25 September 1992)

\begin{abstract}
A variety of sulphonates were tested for their ability to serve as nutrients for Escherichia coli, Enterobacter aerogenes and Serratia marcescens. Cysteate, taurine and isethionate could not serve as sole sources of carbon and energy but, under aerobic conditions, could be utilized as sources of sulphur. Both sulphate and sulphonate supported equivalent cell yields, but the generation times varied with the sulphonate being metabolized. The sulphonate-S of HEPES buffer, dodecane sulphonate and methane sulphonate was also utilized by some strains, whereas the sulphonate-S of taurocholate was not. None of the sulphonates tested served as a sulphur source for growth under anaerobic conditions. Sulphonate utilization appears to be a constitutive trait; surprisingly, however, cells of $E$. coli and Ent. aerogenes utilized sulphate-S in preference to that of sulphonate, when both were present. $E$. coli mutants unable to use sulphate as a source of sulphur because of deficiencies in sulphate permease, ATP sulphurylase, adenylylsulphate kinase (APS kinase) or glutaredoxin and thioredoxin were able to utilize sulphonates; hence sulphate is not an obligatory intermediate in sulphonate utilization. However, mutants deficient in sulphite reductase were unable to utilize sulphonates; therefore, this enzyme must be involved in sulphonate utilization, though it is not yet known whether it acts upon the sulphonates themselves or upon the inorganic sulphite derived from them.
\end{abstract}

\section{Introduction}

Organosulphur compounds in which a sulphur atom at the oxidation state of +4 is covalently linked to a carbon atom are termed sulphonates; these can be either aliphatic or aromatic. Because sulphonates occur naturally, they can be expected to serve as carbon, sulphur and nitrogen sources for bacteria. A few studies (Kondo et al., 1971; Stapley \& Starkey, 1970) have shown that sulphonates such as cysteate and taurine are indeed used for such purposes, but the details of their assimilation are few and incomplete. Even less is known about the utilization of the sulphonate moiety which occurs in more complex molecules such as taurocholate (a bile salt), the sulphonolipids of gliding bacteria (Godchaux \& Leadbetter, 1984) and the most widely distributed sulphonate, sulphoquinovose, present in the lipids of phototrophs (Benson et al., 1959).

This report focuses on sulphonate utilization by a physiologically distinct group of bacteria, the enteric bacteria, in order to ascertain some aspects of their potential to use these molecules as carbon, energy and sulphur sources. Although Neidhardt et al. (1987) do not note this nutritional trait, Roberts et al. (1957) stated

\footnotetext{
*Author for correspondence. Tel. (203) 486 1931; fax (203) 486 1936.
}

that both cysteic acid and taurine can serve as sole source of sulphur for growth of Escherichia coli. More recently, McLaggan \& Epstein (1991) also noted that taurine is utilized as a 'sulphate source' by another strain of $E$. coli, and functions as a 'pseudocompatible' solute in this bacterium.

Members of the Enterobacteriaceae can utilize the sulphur of different sulphur-containing molecules. For example, both Salmonella typhimurium and E. coli utilize sulphate, thiosulphate, sulphite and sulphide as well as thiol compounds (Kredich, 1987). Growth on oxidized forms of inorganic sulphur, e.g. sulphate, requires a complicated set of reactions (assimilatory sulphate reduction) involved in sulphur uptake and its reduction to sulphide (Kredich, 1987). Since little is known about either the details of assimilation of sulphonate-sulphur in $E$. coli, or sulphonate metabolism by other members of the Enterobacteriaceae, we have begun such studies with a view to assessing the role of these bacteria in transformation of sulphonate-sulphur in the natural sulphur cycle.

\section{Methods}

Strains. The parent strains of Escherichia coli K12, E. coli B, E. coli ATCC 25992, Enterobacter aerogenes, Serratia marcescens, Shigella flexneri and Proteus vulgaris were obtained from the University of Connecticut collection. The mutant strains of $E$. coli were provided by 
Barbara J. Bachman (CysA ${ }^{-}$, $\mathrm{CysJ}^{-}$and $\mathrm{CysI}^{-}$), Douglas E. Berg $\left(\mathrm{CysD}^{-} \mathrm{CysN}^{-}\right.$and $\left.\mathrm{CysC}^{-} \mathrm{CysN}^{-}\right)$and Marjorie Russel $\left(\mathrm{Grx}^{-} \mathrm{Trx}^{-} \mathrm{CysA}^{-}\right)$. Cultures were maintained on Trypticase Soy Agar (TSA, Difco) slants and stored at $4^{\circ} \mathrm{C}$. All experiments, with the exception of those employing mutants, used overnight cultures grown in basal salts medium at $25^{\circ} \mathrm{C}$.

Media. The basal salts medium contained $40 \mathrm{mM}-\mathrm{K}_{2} \mathrm{HPO}_{4}$, $15 \mathrm{~mm}-\mathrm{NaH}_{2} \mathrm{PO}_{4} \cdot \mathrm{H}_{2} \mathrm{O}, 19 \mathrm{mM}-\mathrm{NH}_{4} \mathrm{Cl}, 90 \mu \mathrm{M}-\mathrm{CaCl}_{2}$, and $3 \mathrm{~mm}-$ $\mathrm{MgCl}_{2} \cdot 6 \mathrm{H}_{2} \mathrm{O}$. Glucose $(30 \mathrm{mM})$ was the usual carbon source; the sulphur source varied in different experiments, but the concentration of each compound used as a sulphur source was $50 \mu \mathrm{M}$. The growth medium for $E$. coli mutants contained, in addition, $1 \%(\mathrm{w} / \mathrm{v})$ agarose (Type V, Sigma) as a solidifying agent. The lack of growth of wild-type cells in the absence of added sulphur indicated the absence of significant quantities of sulphur-containing contaminants. Because sulphur is present at low levels in reagent-grade chemicals, even a chemically defined medium contains about $7 \mu \mathrm{M}$-sulphur (Kredich, 1987) and will thus support some growth in the absence of an added sulphur source. In order to deplete the glucose/salts medium of such sulphur for studies of constitutivity/inducibility of sulphonate utilization, we used a biological approach: $E$. coli in the mid-exponential growth phase were inoculated into the medium and when growth ceased $\left(\mathrm{OD}_{650} 0 \cdot 25\right)$ as a result of sulphur depletion, the culture was filter-sterilized and the filtrate used as a sulphur-free medium.

Test of sulphonates as sources of carbon and energy. Growth from overnight cultures was inoculated into glucose-free basal salts medium containing sulphate and 30,60 or $90 \mathrm{mM}$ concentrations of one of the different sulphonates-cysteate, taurine or isethionate (2-hydroxyethanesulphonate) - and the $\mathrm{OD}_{650}$ of cultures measured after 3 and $7 \mathrm{~d}$. Where no growth occurred, in order to be certain that sulphonates were not toxic to the cells, glucose was added after $7 \mathrm{~d}$ and the resultant rapid growth was taken to indicate that the sulphonate had no toxic effects. Essentially identical experiments, but in medium lacking added sulphate, were carried out to examine the ability of sulphonates to serve as sole source of carbon, energy and sulphur. Aerobic conditions were attained by shaking $125 \mathrm{ml}$ Erlenmeyer flasks containing $25 \mathrm{ml}$ of medium at 80 strokes $\mathrm{min}^{-1}$; anaerobic conditions were created by using completely filled screw-capped test tubes for culturing.

Test of sulphonates as sole sources of sulphur. The $\mathrm{OD}_{650}$ of cultures tested for utilization of different sulphonates was measured after $24 \mathrm{~h}$ at stationary growth phase. Growth under both aerobic and anaerobic conditions was tested, as described above.

Assessment of sulphate and sulphite as obligatory assimilatory intermediates. E. coli strains mutant in different enzymes of the assimilatory sulphate reductive pathway (sulphate permease, ATP sulphurylase, adenylylsulphate kinase (APS kinase), glutaredoxinthioredoxin and sulphite reductase) were tested for their ability to utilize sulphonates as sole sources of sulphur on agarose-solidified, glucose/salts medium. The ability of the mutants to grow with cysteine/cystine as sulphur source served as a positive control in each experiment.

Tentative assessment of the constitutivity or inducibility of sulphonate utilization. Enterobacter aerogenes was inoculated into a glucose/salts medium containing either sulphate or isethionate as sulphur source; once the cultures reached the mid-exponential growth phase $\left(\mathrm{OD}_{650}\right.$ $0 \cdot 4)$, they were centrifuged $(7700 \mathrm{~g}$ for $10 \mathrm{~min}$ ), and the cells were washed three times in sulphur-free medium and transferred into medium containing either sulphate or isethionate or into sulphur-free medium, to determine if a lag in growth ( $\mathrm{OD}_{650}$ measurements) resulted.

Assessment of competition between sulphate and sulphonate. Cells of Ent. aerogenes were grown on glucose/salts medium containing either sulphate or isethionate as sulphur source. When cultures had reached mid-exponential phase $\left(\mathrm{OD}_{650} 0.4\right)$, cells were harvested by centrifugation $\left(7700 \mathrm{~g}\right.$ for $\left.10 \mathrm{~min}, 4^{\circ} \mathrm{C}\right)$, resuspended and recentrifuged in $0.1 \mathrm{M}$-sodium-phosphate buffer ( $\mathrm{pH} 7.2)$ three times and transferred to flasks containing ${ }^{35}$ S]sulphate $\left(50 \mu \mathrm{M}, 1 \mu \mathrm{Ci} \mu \mathrm{mol}^{-1} ; 37 \mathrm{kBq} \mu \mathrm{mol}^{-1}\right)$ alone or radioactive sulphate and non-radioactive isethionate $(50 \mu \mathrm{M})$. Cultures were incubated with shaking and at successive time intervals $1 \mathrm{ml}$ samples were removed and filtered under vacuum through a $0.45 \mu \mathrm{m}$ pore size polysulphone filter (Gelman Sciences) that had been first wetted with the phosphate buffer. The filter was removed and placed into a vial, $5 \mathrm{ml}$ scintillation cocktail (Opti-fluor, Packard) was added, and the radioactivity was measured in a liquid scintillation counter. These experiments were performed in triplicate.

Reproducibility. All experiments were performed at least three times; growth yields and generation times varied by less than $15 \%$ amongst replicates, and replicates of the results presented in the figures produced essentially identical results.

\section{Results}

\section{Sulphonates do not serve as carbon and energy source}

No growth was observed for any of the strains tested when sulphonates (cysteate, isethionate or taurine) were employed as a sole source of carbon and energy, or of carbon, energy and sulphur, under either aerobic (respiration) or anaerobic conditions. Even at the highest sulphonate concentrations tested $(90 \mathrm{mM})$, no toxicity was observed.

\section{Sulphonates can be utilized as sole sources of sulphur}

When tested under aerobic conditions, cysteate, taurine and isethionate could serve as sole sources of sulphur for different strains. In strains able to use either source, equivalent, but growth-limiting, concentrations of sulphate and sulphonates supported equivalent final cell yields (Table 1). Generation times, however, often varied with the sulphonate utilized: isethionate supported the most rapid growth and cysteate the slowest (Table 2); for some strains the growth rate using a sulphonate or sulphate was identical. In addition to the short-chain aliphatic sulphonates, a few other compounds, both simple and complex, could be used as sulphur source by some strains (Table 3). Some enteric bacteria were unable to use any of the sulphonates tested as a source of sulphur: (e.g. Sal. typhimurium, P. vulgaris, Shig. flexneri and a fresh isolate of $E$. coli) (Tables 1 and 3). Of interest is the observation that none of the sulphonates utilized under aerobic conditions were used as sulphur source for anaerobic growth $\left(\mathrm{OD}_{650} \leqslant 0 \cdot 1\right)$.

\section{Sulphate and sulphite: obligatory intermediates in sulphonate assimilation?}

E. coli mutants in sulphate permease $\left(\mathrm{CysA}^{-}\right)$, ATP sulphurylase $\left(\mathrm{CysD}^{-} \mathrm{CysN}^{-}\right)$, ATP sulphurylase and APS kinase $\left(\mathrm{Cys}^{-} \mathrm{CysN}^{-}\right)$and glutaredoxin, thioredoxin, 
Table 1. Sulphonate-sulphur utilization by some strains of the family Enterobacteriaceae

Growth was measured as $\mathrm{OD}_{650}$ at the stationary phase of growth of cultures growing in glucose + mineral salts medium containing the indicated sole added source of sulphur (see Methods). When no sulphur source was added, $\mathrm{OD}_{650}$ was always $\leqslant 0 \cdot 2$.

\begin{tabular}{|c|c|c|c|c|}
\hline \multirow[b]{2}{*}{ Strain } & \multicolumn{4}{|c|}{ Maximal $\mathrm{OD}_{650}$ on: } \\
\hline & Sulphate & Cysteate & Isethionate & Taurine \\
\hline Enterobacter aerogenes & $1 \cdot 2$ & $1 \cdot 1$ & $1 \cdot 2$ & 1.4 \\
\hline Serratia marcescens & $1 \cdot 8$ & 1.6 & 1.6 & 1.5 \\
\hline Escherichia coli $\mathrm{K} 12$ & 0.9 & $1 \cdot 2$ & $1 \cdot 1$ & 0.9 \\
\hline Escherichia coli ${ }^{*}$ & 0.9 & $0 \cdot 1$ & 0.2 & 0.2 \\
\hline Shigella flexneri & $1 \cdot 2$ & $0 \cdot 1$ & $0 \cdot 2$ & 0.2 \\
\hline Proteus vulgaris & 0.9 & 0.2 & $0 \cdot 1$ & $0 \cdot 2$ \\
\hline Salmonella typhimurium & $1 \cdot 1$ & 0.1 & 0.2 & 0.2 \\
\hline
\end{tabular}

* This is a strain isolated from a faecal sample.

Table 2. Generation times of some strains of enteric bacteria when growing on sulphonates as a sole source of sulphur

Bacteria were grown with aeration at $25^{\circ} \mathrm{C}$ in glucose + mineral salts medium containing the indicated sole sulphur source $(50 \mu \mathrm{M})$; growth was measured by changes in $\mathrm{OD}_{650}$ at intervals during the exponential growth phase. For purposes of comparison the generation time of $E$. coli $\mathrm{K} 12$ at $37^{\circ} \mathrm{C}$ in standard Luria broth was $30 \mathrm{~min}$, while in glucose + mineral salts with sulphate as sulphur source it was $45 \mathrm{~min}$.

\begin{tabular}{lcccc}
\hline \hline & \multicolumn{4}{c}{ Generation time (min) on: } \\
\cline { 2 - 5 } Strain & Sulphate & Cysteate & Isethionate & Taurine \\
\hline Enterobacter aerogenes & 60 & 150 & 60 & 120 \\
Serratia marcescens & 60 & 150 & 60 & 60 \\
Escherichia coli K12 & 90 & 150 & 90 & 150 \\
\hline \hline
\end{tabular}

Table 3. Utilization of other sulphonates by some strains of the family Enterobacteriaceae

Growth was measured as $\mathrm{OD}_{650}$ at the stationary phase of growth of cultures growing in glucose/mineral salts medium containing the indicated sole added source of sulphur (see Methods). The $\mathrm{OD}_{650}$ when no sulphur source was added was always $\leqslant 0 \cdot 2$.

\begin{tabular}{lcccc}
\hline \hline & \multicolumn{4}{c}{ Maximal OD $_{650}$ on: } \\
\cline { 2 - 5 } Strain & $\begin{array}{c}\text { Dodecane } \\
\text { sulphonate }\end{array}$ & $\begin{array}{l}\text { Tauro- } \\
\text { cholate }\end{array}$ & HEPES & $\begin{array}{c}\text { Methane } \\
\text { sulphonate }\end{array}$ \\
\hline Enterobacter aerogenes & $0 \cdot 2$ & 0.2 & $1 \cdot 1$ & $1 \cdot 2$ \\
Serratia marcescens & $0 \cdot 2$ & 0.2 & $1 \cdot 2$ & $1 \cdot 2$ \\
Escherichia coli K12 & $1 \cdot 1$ & $0 \cdot 1$ & 0.8 & $1 \cdot 2$ \\
Escherichia coli (ATCC & $0 \cdot 2$ & 0.2 & 0.9 & ND \\
25992) & $0 \cdot 2$ & 0.2 & 0.2 & ND \\
Shigella flexneri & $0 \cdot 2$ & 0.2 & 0.2 & ND \\
Proteus vulgaris & & & & \\
\hline \hline
\end{tabular}

ND, Not determined.

and sulphate permease $\left(\mathrm{Grx}^{-} \operatorname{Trx}^{-} \mathrm{CysA}^{-}\right)$used isethionate as the sole source of sulphur (Table 4); mutants in the sulphite reductase $\left(\mathrm{CysJ}^{-}\right.$and $\mathrm{CysI}^{-}$) did not (Table 4). The mutants grew well on cysteine/cystine as sulphur source.

\section{Sulphonate utilization appears to be constitutive}

No growth lag was observed when cells grown on glucose/salts medium containing sulphate as a sole source of sulphur were washed and resuspended in 
Table 4. Isethionate utilization by E. coli mutants

The mutant strains were inoculated onto a glucose + mineral-salts medium containing the indicated sulphur source and solidified with agarose (see Methods).

\begin{tabular}{|c|c|c|c|}
\hline \multirow[b]{2}{*}{ Strains (mutant in) } & \multicolumn{3}{|c|}{ Growth with listed sulphur source*: } \\
\hline & Sulphate & Sulphite & Isethionate \\
\hline CysA $^{-}$(sulphate permease) & - & + & + \\
\hline $\mathrm{CysD}^{-} \mathrm{CysN}^{-}$(ATP sulphurylase) & - & + & + \\
\hline $\mathrm{CysC}^{-} \mathrm{CysN}^{-}$(sulphurylase and APS kinase) & - & + & + \\
\hline $\begin{array}{l}\mathrm{Grx}^{-} \mathrm{Trx}^{-} \mathrm{Cys}^{-} \text {(thioredoxin, glutaredoxin and } \\
\text { sulphate permease) }\end{array}$ & - & + & + \\
\hline CysJ J- $^{-}$CysI $^{-}$(sulphite reductase) & - & - & - \\
\hline
\end{tabular}

$*+$, Confluent growth on the solid medium, - , faint background growth, or no growth.

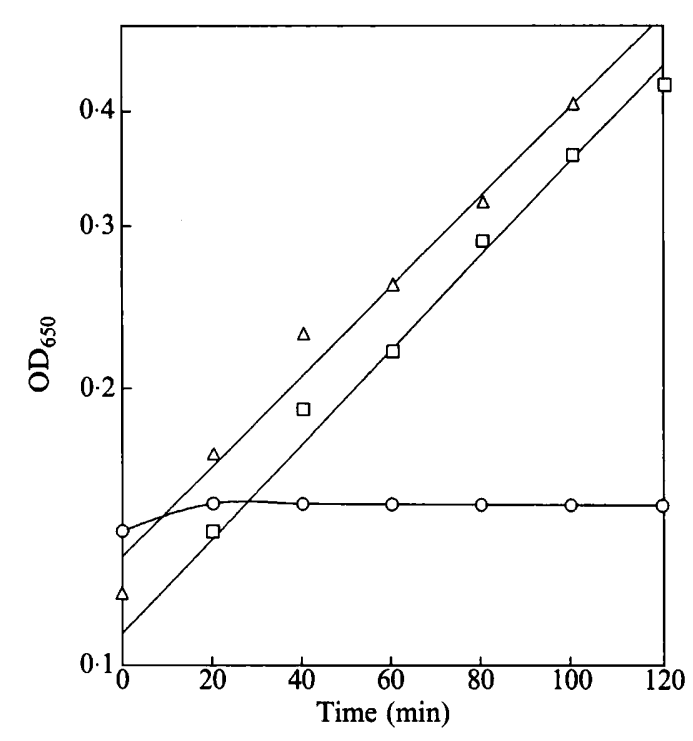

Fig. 1. Absence of a lag phase in growth on sulphonate. Cells of Ent. aerogenes growing on either sulphate or sulphonate as sulphur source in glucose + mineral salts medium were washed and transferred to the same medium containing sulphate $(\square)$, isethionate $(\triangle)$ or no added sulphur source $(O) . \mathrm{OD}_{650}$ was measured at the times indicated. See Methods for more details.

medium containing isethionate as sole sulphur source (Fig. 1). Absence of a growth lag was also observed when sulphonate-grown cells were washed and transferred to a medium containing sulphate (results not shown). No sustained growth was observed when cells growing on either sulphate or sulphonate were transferred into sulphur-free medium.

\section{Sulphate-S is used in preference to that of a sulphonate}

Cells of Ent. aerogenes grown in a medium in which $\left[{ }^{35}\right.$ S]sulphate was the sole sulphur source and those grown in a medium containing both $\left[{ }^{35} \mathrm{~S}\right]$ sulphate and non-radioactive isethionate incorporated an identical

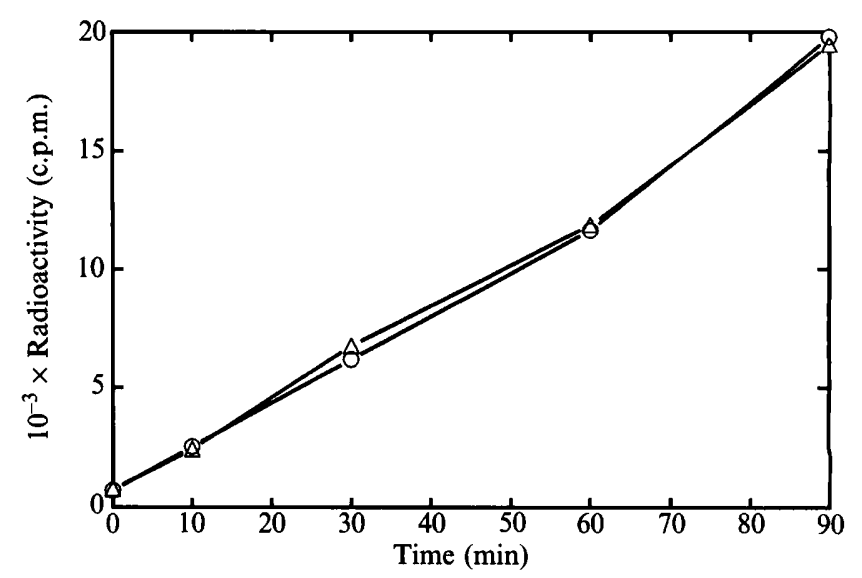

Fig. 2. Preferential use of sulphate over sulphonate in a typical competition experiment. Cells of Ent. aerogenes were incubated with $\left[{ }^{35} \mathrm{~S}\right]$ sulphate $(\mathrm{O})$ or with $\left[{ }^{35} \mathrm{~S}\right]$ sulphate plus an equimolar amount of non-radioactive isethionate $(\triangle)$. Radioactivity incorporated into equivalent amounts of cell material in each culture was measured at the times indicated. See Methods for more details.

amount of sulphate-S per unit of biomass (Fig. 2). Hence, isethionate did not compete effectively with sulphate as a sulphur source. In contrast (as would be expected), cells growing in cysteine-containing medium did not incorporate $\left[{ }^{35} \mathrm{~S}\right]$ sulphate (results not shown).

\section{Discussion}

Some knowledge has been accumulated in recent years on the assimilation of several sulphonates by different bacteria, e.g. pseudomonads (Locher et al., 1989; Nortemann et al., 1986; Thurnheer et al., 1990; Wittich et al., 1988); unfortunately, most of these studies paid little attention to the extent and means by which enteric bacteria, the focus of this study, could incorporate the sulphur of these molecules into cellular sulphur compounds. Although the family Enterobacteriaceae does 
not have a broad nutritional spectrum, some species exist in soil and water (where sulphonates are quite abundant), and some are found in intestinal tracts where at least one sulphonate, taurocholate, occurs naturally; therefore, some sulphonate assimilation by these bacteria could be expected.

The ability of cysteate and taurine to serve as sole sulphur source for a strain of $E$. coli has been demonstrated earlier (Roberts et al., 1957). We have established that these, and other sulphonates, can also be utilized by some other (but not all) $E$. coli strains, as well as by a strain of Ent. aerogenes and one of Ser. marcescens. The finding that methane sulphonate (a major product of the photochemical oxidation, in the atmosphere, of dimethyl sulphide) can be used as a source of sulphur by enteric bacteria is very significant. Baker et al. (1991) recognized that this molecule serves as a source of carbon for methylotrophic bacteria; it is now clear that heterotrophic bacteria can also metabolize methane sulphonate as a source of sulphur.

None of the organisms tested were able to utilize even short-chain aliphatic sulphonates as sole source of carbon and energy or as sole source of carbon, energy and sulphur. This is somewhat surprising since the result of an expected oxidative cleavage of the $\mathrm{C}-\mathrm{S}$ bond should be carbon compounds quite similar to those molecules (e.g. acetate, ethanol) that are known to serve as sole carbon and energy sources for $E$. coli. It remains to be seen whether sulphate or sulphite inhibit the activity of particular sulphonate-degrading enzymes.

Even more surprising is the lack of sulphonate utilization under anaerobic conditions, since we have found no evidence for sulphonate toxicity. In addition, the results from the study of several mutant strains provide no suggestion that sulphate is an obligatory intermediate (and thus that molecular oxygen might be necessary for an oxidative cleavage of the $\mathrm{C}-\mathrm{S}$ bond) in the conversion of sulphonate-sulphur to that of cellular intermediates.

Thus, several intriguing aspects of the utilization of sulphonate-sulphur emerge. The fact that the sulphur of several different sulphonates can be assimilated by these bacteria, and the observations (Roberts et al., 1957; this paper) that (a) growth on sulphonates does not result in inhibition or repression of sulphate assimilation and (b) sulphate-sulphur is used in preference to that of isethionate when both are present, combine to emphasize the apparent novelty of sulphonate metabolism, and may indicate that a direct assimilatory reduction of sulphonates occurs. Such a possibility is consistent with essentially identical observations on the assimilation of sulphonate sulphur in pseudomonads (A. P. Seitz, E. R. Leadbetter and W. Godchaux, III, unpublished results) as well as several other bacteria (Zurrer et al., 1987).
Since the several mutants deficient in different aspects of the ability to reduce sulphate to sulphite are all able to utilize sulphonate-sulphur, it is clear that in these strains of E. coli, at least, sulphur at this oxidation state $(+4)$ can be assimilated without prior oxidation to sulphate (+6). Given the need for ATP expenditure in the reduction of sulphate to sulphite, it would seem that these bacteria are taking advantage of the reduced state of sulphonate-sulphur and are not being wasteful by first oxidizing it only then to reduce it by the assimilatory sulphate reduction pathway.

Whether sulphite itself is released from these sulphonates and subjected to further reduction, or whether reduction takes place with the $\mathrm{C}-\mathrm{S}$ bond intact has not been resolved by the demonstration that mutant strains $\left(\mathrm{CysJ}^{-}, \mathrm{CysI}^{-}\right)$deficient in either of the subunits of sulphite reductase are unable to utilize sulphonate sulphur. Sulphite (or in some instances, sulphate) has been shown to be released from some arylsulphonates when the latter serve either as sole source of carbon and energy (Cain \& Farr, 1968) or as sulphur source alone (Zurrer et al., 1987). It may be instructive to consider that growth on sulphite-sulphur, for example, inhibits sulphate assimilation while growth on sulphonate (the sulphur of which has an oxidation state indentical to that in sulphite) does not; this can be interpreted to indicate that sulphite per se is not released during assimilation of sulphonate-sulphur.

The basis for preferential utilization of sulphatesulphur, as opposed to that of sulphonate, and the nature of the intermediates in the metabolism of sulphonatesulphur should be revealed by the more detailed studies of the enzymology of sulphonate utilization by enteric bacteria that are in progress in our laboratory.

We thank Angelica P. Seitz for helpful suggestions. This research was supported, in part, by Contract N00014-88-K-0120 from The Office of Naval Research (USA) and the University of Connecticut Research Foundation.

\section{References}

Baker, S. C., Kelly, D. P. \& Murrell, J. C. (1991). Microbial degradation of methanesulphonic acid: a missing link in the biogeochemical sulphur cycle. Nature, London 350, 627-628.

Benson, A. A., Daniel, H., Wiser, R. (1959). A sulfolipid in plants. Proceedings of the National Academy of Sciences of the United States of America 45, 1582-1587.

CAIN, R. B. \& FARR, D. R. (1968). Metabolism of arylsulphonates by microorganisms. Biochemical Journal 106, 859-877.

Godchaux, W., III \& LEADbetTER, E. R. (1984). Sulfonolipids of gliding bacteria: structures of the $\mathrm{N}$-acylaminosulfonates. Journal of Biological Chemistry 259, 2982-2990.

Kondo, H., Anada, H., Ohsawa, K. \& Ishimoto, M. (1971). Formation of sulfoacetaldehyde from taurine in bacterial extracts. Journal of Biochemistry 69, 621-623.

KREDiCH, N. M. (1987). Biosynthesis of cysteine. In Escherichia coli and Salmonella typhimurium. Cellular and Molecular Biology, pp. 
419-427. Edited by F. C. Neidhardt and others. Washington, DC: American Society for Microbiology.

LOCHER, H. H., THURNHEER, T., LeIsINGER, T. \& COOK, A. M. (1989). 3-Nitrobenzenesulfonic acid, 3-aminobenzenesulfonic acid and 4aminobenzenesulfonic acid as sole carbon sources for bacteria. Applied and Environmental Microbiology 55, 492-494.

MCLAGGAN, D. \& EPSTEIN, W. (1991). Escherichia coli accumulates the eukaryotic osmolyte taurine at high osmolarity. FEMS Microbiology Letters 81, 209-214.

Neidhardt, F. C., Ingraham, J. L., Low, K. B., Magasanik, B., SCHAECHTER, M. \& UMBARGER, H. E. (editors) (1987). Escherichio coli and Salmonella typhimurium. Cellular and Molecular biology. Washington, DC: American Society for Microbiology.

Nortemann, B., Baumgarten, J., Rast, H. G. \& Knackmuss, H. J. (1986). Bacterial communities degrading amino- and naphthalene-2sulfonates. Applied and Environmental Microbiology 52, 1195-1202. Roberts, R. B., Abelson, P. H., Cowie, D. B., Bolton, E. T. \&
Britten, R. J. (1957). Studies of Biosynthesis in Escherichia coli. Washington, DC: Carnegie Institution of Washington.

Stapley, E. \& Starkey, R. (1970). Decomposition of cysteic acid and taurine by soil micro-organisms. Journal of General Microbiology 64, $77-84$.

Thurnheer, T., Zurrer, D., Hoglinger, O., Leisinger, T. \& COOK, A. M. (1990). Initial steps in the degradation of benzene sulfonic acid, 4-toluene sulfonic acids, and orthanilic acid in Alcaligenes sp. strain 0-1. Biodegradation 1, 55-64.

WitTich, R. M., RAST, H. G. \& KNaCKmuss, H. J. (1988). Degradation of naphthalene-2,6- and naphthalene-1,6-disulfonic acid by a Moraxella sp. Applied and Environmental Microbiology 53, 1459-1463.

ZurRer, D., CoOK, A. M, \& LeIsINGer, T. (1987). Microbial desulfonation of substituted naphthalenesulfonic acids and benzenesulfonic acids. Applied and Environmental Microbiology 53, 1459-1463. 